\title{
High Temperature Fatigue Life Evaluation Using Small Specimen*)
}

\author{
Shuhei NOGAMI, Chiaki HISAKA ${ }^{1)}$, Masaharu FUJIWARA ${ }^{1)}$, \\ Eichi WAKAI ${ }^{2)}$ and Akira HASEGAWA \\ Department of Quantum Science and Energy Engineering, Graduate School of Engineering, \\ Tohoku University, Sendai, Miyagi 980-8579, Japan \\ 1) Kobe Material Testing Laboratory Co., Ltd., Kako-gun, Hyogo 675-0155, Japan \\ 2) Japan Atomic Energy Agency, Tokai, Ibaraki 319-1195, Japan
}

(Received 12 January 2017 / Accepted 6 April 2017)

\begin{abstract}
For developing the high temperature fatigue life evaluation method using small specimen, the effect of specimen size and test environment on the high temperature fatigue life of the reduced activation ferritic/martensitic steel, F82H-IEA, was investigated at $550{ }^{\circ} \mathrm{C}$ under the total strain range of $0.5-1.2 \%$ using a new high temperature low cycle fatigue testing machine for the small round-bar specimen. No significant effect of the test environment (oxidation) on the fatigue life was observed in the standard-size specimen, whereas the slight reduction of the fatigue life due to that was indicated in the small-size specimen, especially at the final fracture stage of the test. It could be concluded that the new high temperature low cycle fatigue testing machine of the present study could satisfy the minimum requirements for the high temperature low cycle fatigue life evaluation using small specimen because the fatigue life data obtained using this testing machine could be acceptable based on the comparison with the previous studies data. To improve the reliability and the applicability of this test technology, further evaluations under the wider test temperature and strain conditions are expected in future.
\end{abstract}

(c) 2017 The Japan Society of Plasma Science and Nuclear Fusion Research

Keywords: small specimen test technique, fatigue life, reduced activation ferritic/martensitic steel, specimen size, test environment, oxidation

DOI: $10.1585 /$ pfr.12.1405022

\section{Introduction}

Study on the neutron irradiation effects on the structural materials of fusion reactors is essential to realize their structural design and operation with long term reliability. For doing that, neutron irradiation tests using fission test reactors and accelerator-based ion irradiation tests have been carried out worldwide. However, these test techniques cannot simulate the simultaneous transmutation effect completely, which is unique to the $14 \mathrm{MeV}$ neutron irradiation environment of the fusion reactor. The $14 \mathrm{MeV}$ neutron irradiation leads to a simultaneous helium production with relatively high density under the displacement damage formation. Therefore, the $14 \mathrm{MeV}$ neutron sources for material irradiation are expected to clarify the fusion neutron irradiation effects on the structural materials.

Reduction of the specimen volume is strongly demanded for the neutron irradiation test using $14 \mathrm{MeV}$ neutron sources because the available volume for the material irradiation will be very limited. Moreover, specimen volume should be decreased to realize the uniform specimen temperature and irradiation damage with no significant distribution in one specimen because the volume suffered by the uniform neutron flux will be limited. To realize the mechanical testing using a smaller specimen than the ones

author'se-mail: shuhei.nogami@qse.tohoku.ac.jp

*) This article is based on the invited talk at the 33rd JSPF Annual Meeting (2016, Tohoku). recommended in the test standards such as the ASTM and the JIS, several types of the small specimen have been proposed and utilized for the fusion reactor materials research. However, these specimens did not always show the same mechanical properties (strength, elongation, and life, etc.) as the recommended standard specimen. Thus, the optimization of specimen is a key issue for developing a reliable mechanical testing technology using small specimen.

The fatigue life of structural materials and the effect of neutron irradiation on it must be understood to design fusion reactors and to predict their residual life during operation because they must support cyclic loads under neutron irradiation. The authors have been developing a low cycle fatigue testing technology using small specimen [1-3]. The specimen utilized for this technology is a round-bar specimen with a test section diameter of around $1 \mathrm{~mm}$. In the room temperature low cycle fatigue tests, this specimen produced the same fatigue life as the recommended specimen in the test standards, while the small hourglass-shaped specimen, which has been utilized for the material irradiation tests for about a decade [4-10], was clarified to show the different fatigue life from that.

For fusion reactors development, material properties under the operation temperature should be clarified. Therefore, the possibility of the high temperature fatigue testing using small specimen should be prepared for future evaluations of the $14 \mathrm{MeV}$ neutron-irradiated materials. As 
the first step to the evaluation of the high temperature fatigue life using small specimen, we have developed a new high temperature low cycle fatigue testing machine for the small round-bar specimen. In this paper, the effect of specimen size and test environment (in air vs. in vacuum) on the high temperature fatigue life of the reduced activation ferritic/martensitic (RAFM) steel was investigated.

\section{Experimental Procedure}

The Japanese Fe-8Cr-2W RAFM steel, F82H-IEA, developed by the Japan Atomic Energy Agency (JAEA) was employed in this study. This material was normalized at $1040{ }^{\circ} \mathrm{C}$ for $40 \mathrm{~min}$ and then tempered at $750{ }^{\circ} \mathrm{C}$ for $1 \mathrm{~h}$ [11]. The average prior austenitic grain diameter of the F82H-IEA was $105 \mu \mathrm{m}$ [1], which was evaluated based on the ASTM E112-85 standard [12]. The Vickers hardness of the F82H-IEA was Hv224 under the applied load of $9.8 \mathrm{~N}$ at R.T. [1].

To investigate the effects of specimen size on the fatigue life, two kinds of the round-bar specimen were examined. The test section diameters and lengths of them were $7 \mathrm{~mm}$ and $19 \mathrm{~mm}$ (RB-7 specimen) and $1 \mathrm{~mm}$ and $3.4 \mathrm{~mm}$ (RB-1 specimen), respectively (in this paper, a round-bar specimen with test section diameter of $\mathrm{x} \mathrm{mm}$ is called " $\mathrm{RB}$ x"). The shape and geometry of the RB-7 and RB-1 specimens are shown in Fig. 1. Moreover, to investigate the effects of test environment (in air vs. in vacuum) on the fatigue life, fatigue tests was conducted in air environment in this study and the results were compared with the fatigue life obtained in vacuum environment [13]. All the fatigue tests of the present study were carried out at $550{ }^{\circ} \mathrm{C}$ in air. A completely reversed push-pull condition was applied, and the total strain range was controlled using a triangular wave $(R=-1)$. Fatigue tests using the RB-7 and RB-1 specimens were carried out under axial strain control using a hydraulic testing machine with a $100 \mathrm{kN}$ load cell fabricated by MTS Systems Corp., U.S.A. and using a electromotive piezo-driven testing machine with a $1 \mathrm{kN}$ load cell fabricated by Kobe Material Testing Laboratory, Co., Ltd., Japan, respectively. The axial strain was measured using an extensometer attached directly to the specimen. The extensometer for the RB-7 specimen consisted of two knife-edge probes, which was a very common extensometer recommended in the test standards [14]. The extensometer for the RB-1 specimen was originally developed by Kobe Material Testing Laboratory, Co., Ltd., Japan. Figure 2 shows the photos and schematic illustrations of the fatigue testing machine and its extensometer for the RB-1 specimen. Four alumina bars (two bars per each side) with different length were pressed against the test section of the specimen and the distance of two bars of one side was measured by a laser extensometer for the axial strain control. The total strain range $\left(\Delta \varepsilon_{\mathrm{t}}\right)$ and the strain rate were $0.5,0.8$, and $1.2 \%$ and $0.1 \% / \mathrm{s}$, respectively, for both RB-7 and the RB-1 specimens. For all the fatigue

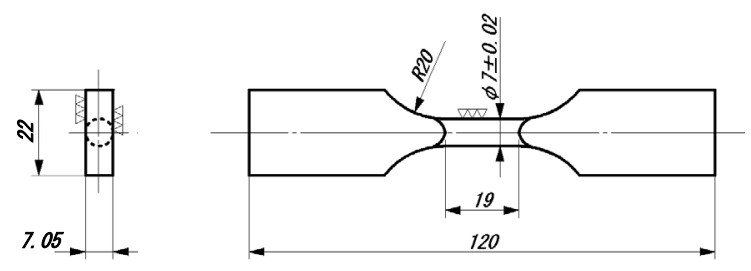

(a) RB-7 specimen

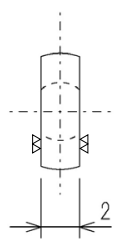

Unit: mm

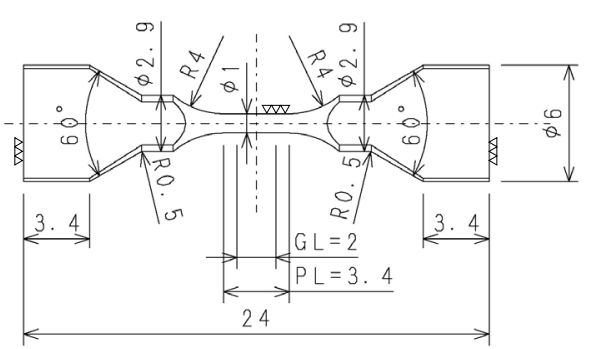

(b) RB-1 specimen

Fig. 1 Shape of fatigue specimens ((a): RB-7 specimen, (b): RB-1 specimen).
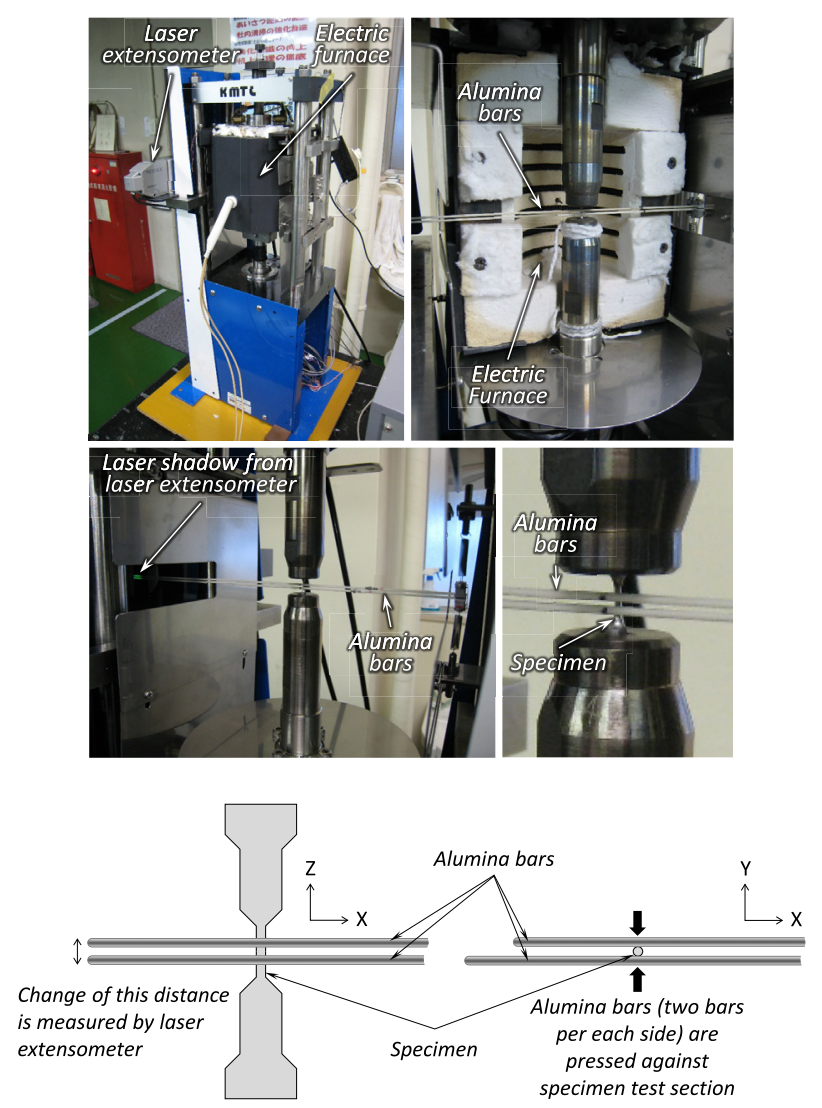

Fig. 2 Photos and schematic illustrations of fatigue testing machine and its extensometer for RB-1 specimen developed by Kobe Material Testing Laboratory, Co., Ltd., Japan.

tests in this study, the fatigue life $\left(N_{\mathrm{f}}\right)$ was defined as the number of cycles at which the tensile peak stress dropped to $75 \%$ from the extrapolated line of the cyclic softening trend. 


\section{Results and Discussion}

Figure 3 shows the relationship between total strain range $\left(\Delta \varepsilon_{\mathrm{t}}\right)$ and number of cycles to failure $\left(N_{\mathrm{f}}\right)$ of the RB1 specimen tested at R.T. in air [1] and tested at $550{ }^{\circ} \mathrm{C}$ in air, the RB-4 specimen tested at R.T. in air [1], the RB7 specimen tested at R.T. in air $[1,13]$, tested at $550^{\circ} \mathrm{C}$ in air, and tested at $550^{\circ} \mathrm{C}$ in vacuum [13], and the RB10 specimen tested at R.T. in air [13] and tested at $550^{\circ} \mathrm{C}$ in vacuum [13]. The Manson-Coffin type regression curve for the fatigue life of the standard specimen tested at R.T. $\left(\Delta \varepsilon_{\mathrm{t}}=105 N_{\mathrm{f}}^{-0.66}+0.80 N_{\mathrm{f}}^{-0.07}[1]\right)$ is also plotted for comparison. In general, the fatigue life at $550^{\circ} \mathrm{C}$ was shorter than that at R.T. regardless of the specimen size and test environment. Based on the comparison with the regression curve of the room temperature test, $40-80 \%$ and $75-90 \%$ reduction in comparison with the room temperature fatigue life were observed at $550^{\circ} \mathrm{C}$ under high strain $(\sim 1.2 \%)$ and low strain conditions $(\sim 0.5 \%)$, respectively. Because the strength rather than the ductility is dominant factor for the low strain fatigue test with low (no) plastic strain, the influence of the strength reduction with temperature increment could be significant for the fatigue life of the F82H-IEA at $550^{\circ} \mathrm{C}$ in the present study.

In case of the RB-7 specimen at $550^{\circ} \mathrm{C}$, the fatigue life obtained in air was slightly longer than that obtained in vacuum as shown in Fig. 3. However, according to the previous reports [15-19], the fatigue life of the 9-12Cr martensitic steels obtained in vacuum was longer than that obtained in air. For example, Fournier et al. reported that the fatigue life of the modified $9 \mathrm{Cr}$-1Mo martensitic steels obtained at $550^{\circ} \mathrm{C}$ in vacuum and in air, which has a similar microstructure to the F82H-IEA $[15,16]$. In this case, the fatigue life in vacuum was longer than that in air (1$2 \times 10^{4}$ cycles in air and $4 \times 10^{4}$ cycles in vacuum at $\Delta \varepsilon_{\mathrm{t}}=0.5 \%, 3-4 \times 10^{3}$ cycles in air and $1-2 \times 10^{4}$ cycles in vacuum at $\Delta \varepsilon_{\mathrm{t}}=0.7 \%$ ), which was explained by the lower crack propagation rate in vacuum than in air due to (almost) no oxidation effects. The fact that the fatigue life in air was longer than in vacuum in the present study was opposite phenomena against the fatigue life reduction in those previous reports, which was generally explained by the oxidation-enhanced fatigue crack initiation and propagation mechanism $[15-18,20]$. On the other hand, based on the fact that the difference in the fatigue life of the RB-7 specimen between in air and in vacuum was not so large, which did not exceed the scatter range of a factor of 2 of the regression curve of the room temperature test shown in Fig. 3, and fact that the detrimental effect of oxidation on the fatigue life occurred under relatively low strain range conditions $[18,19]$, it could be assumed that the effect of the oxidation on the fatigue life of the F82H-IEA was relatively small or negligible under the test condition of the present study.

As shown in Fig. 3, regardless of the total strain range, the fatigue life of the RB-1 specimens obtained at $550^{\circ} \mathrm{C}$ in air was slightly shorter than that of the RB-7 specimens

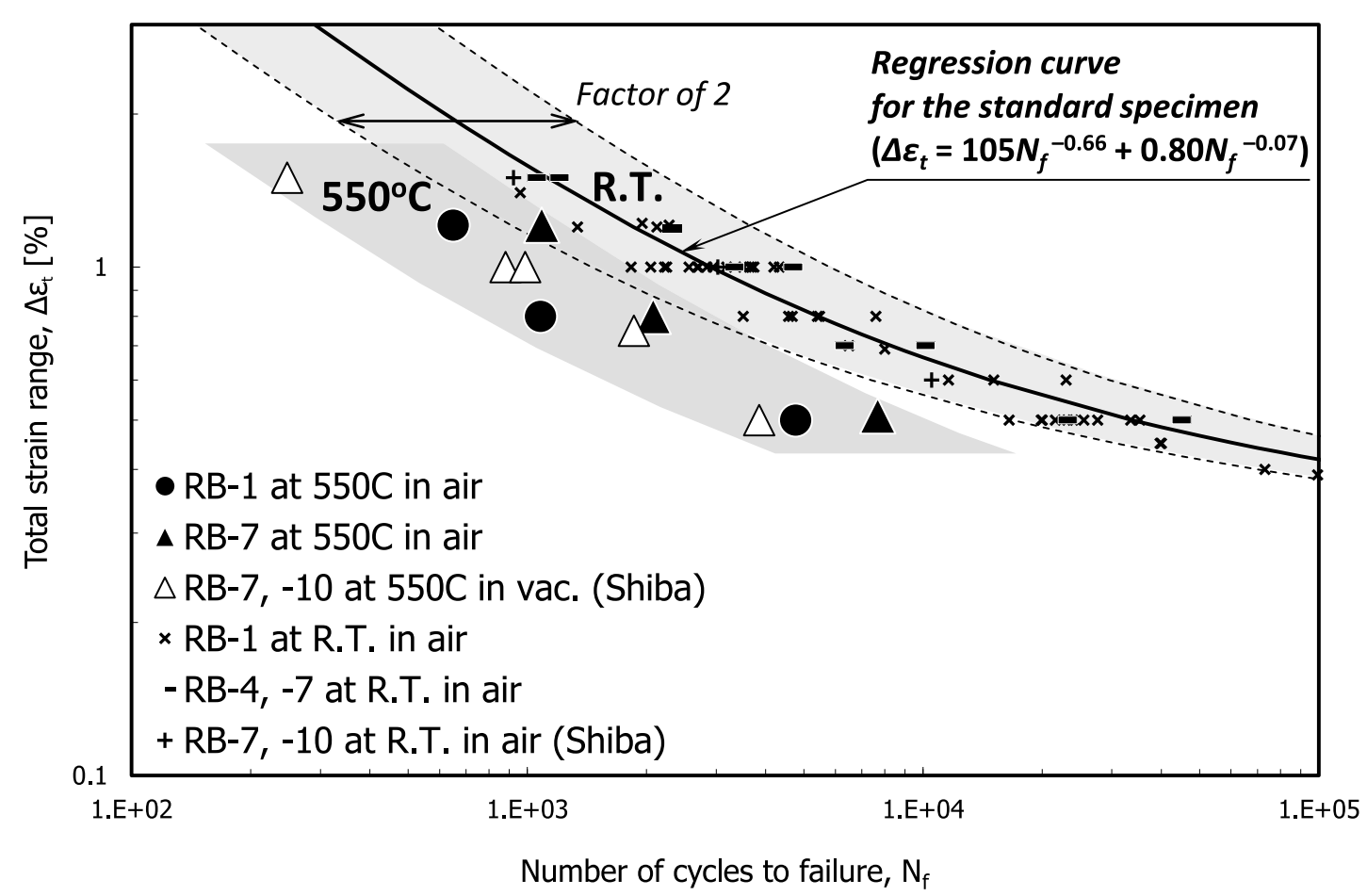

Fig. 3 Relationship between total strain range $\left(\Delta \varepsilon_{\mathrm{t}}\right)$ and number of cycles to failure $\left(N_{\mathrm{f}}\right)$ of RB-1 specimen tested at R.T. in air [1] and tested at $550^{\circ} \mathrm{C}$ in air, RB-4 specimen tested at R.T. in air [1], RB-7 specimen tested at R.T. in air [1, 13], tested at $550^{\circ} \mathrm{C}$ in air, and tested at $550^{\circ} \mathrm{C}$ in vacuum [13], and RB-10 specimen tested at R.T. in air [13] and tested at $550^{\circ} \mathrm{C}$ in vacuum [13]. 

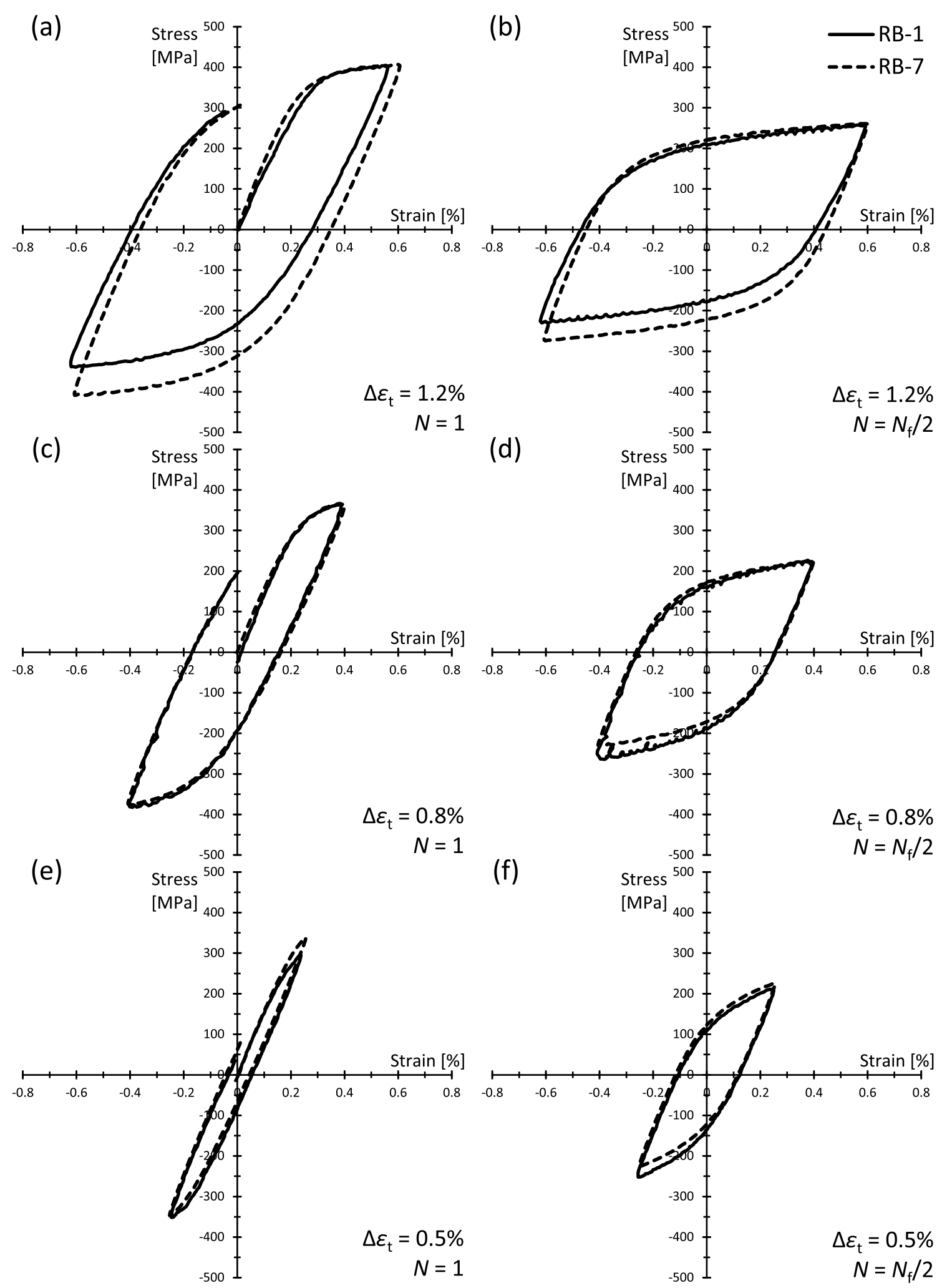

Fig. 4 Relationship between applied stress and applied strain of RB-7 and RB-1 specimens at $550{ }^{\circ} \mathrm{C}$ in air ((a): $N=1$ under $\Delta \varepsilon_{\mathrm{t}}=1.2 \%$, (b): $N=1$ under $\Delta \varepsilon_{\mathrm{t}}=0.8 \%$, (c): $N=1$ under $\Delta \varepsilon_{\mathrm{t}}=0.5 \%$, (d): $N=N_{\mathrm{f}} / 2$ under $\Delta \varepsilon_{\mathrm{t}}=1.2 \%,(\mathrm{e}): N=N_{\mathrm{f}} / 2$ under $\Delta \varepsilon_{\mathrm{t}}=0.8 \%$, (f): $N=N_{\mathrm{f}} / 2$ under $\Delta \varepsilon_{\mathrm{t}}=0.5 \%$ ).

obtained at $550{ }^{\circ} \mathrm{C}$ in air. Figures 4 and 5 show the relationships between applied stress and applied strain and between peak stress $\left(\sigma_{\text {peak }}\right)$ and number of cycles $(N)$ of the RB-7 and RB-1 specimens tested at $550^{\circ} \mathrm{C}$ in air, respec- tively. No significant difference in the shape of the hysteresis curves at the first cycle and at the $N_{\mathrm{f}} / 2$ between them were observed regardless of the total strain range, as shown in Fig. 4. On the other hand, the cyclic softening curves 


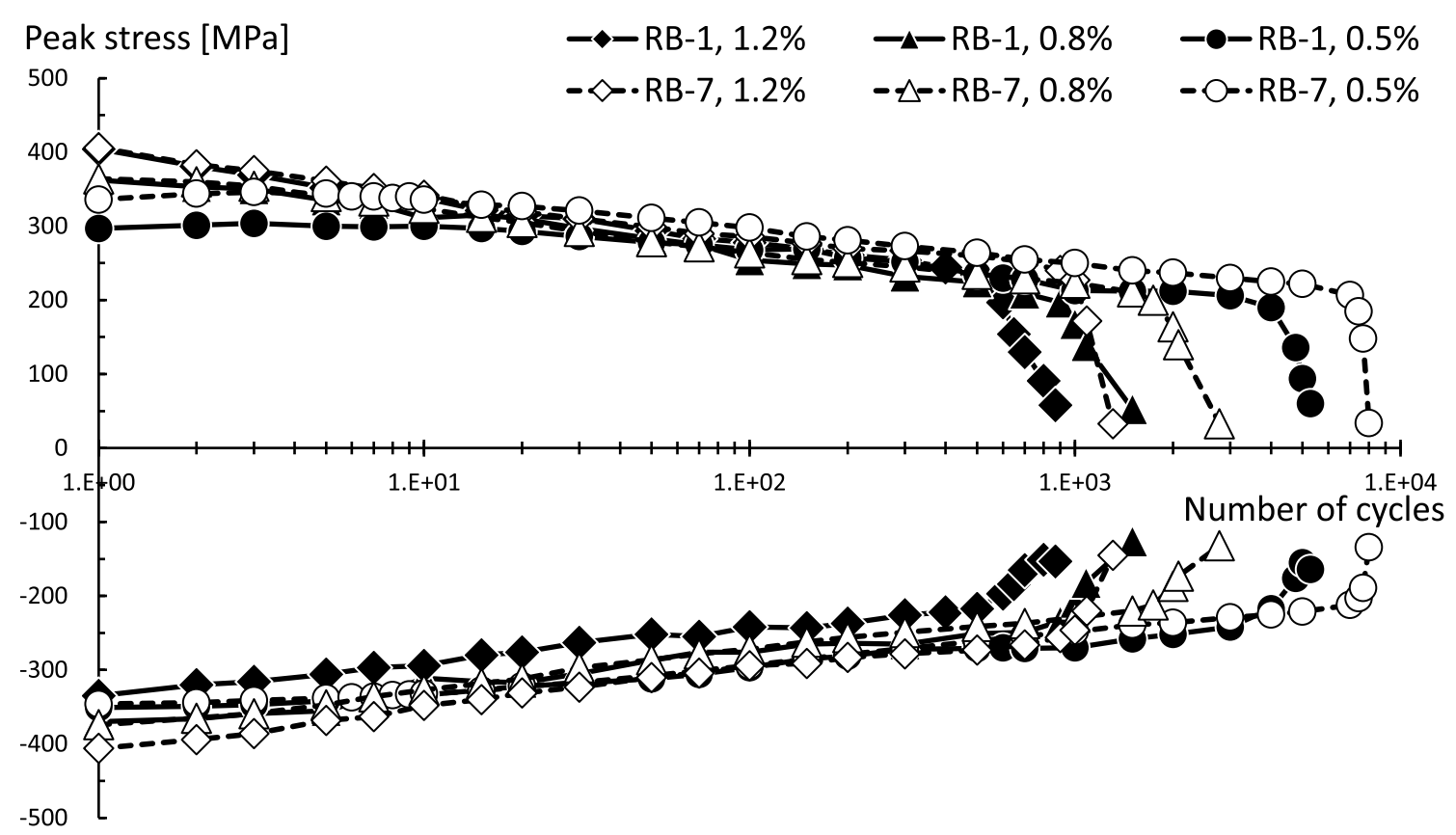

Fig. 5 Relationship between peak stress $\left(\sigma_{\text {peak }}\right)$ and number of cycles $(N)$ of RB-7 and RB- 1 specimens at $550{ }^{\circ} \mathrm{C}$ in air under total strain range of $1.2 \%, 0.8 \%$, and $0.5 \%$.

showed no significant difference between them until the final fracture stage of the tests, whereas they showed clear difference at the final fracture stage, as shown in Fig. 5, which might influence the fatigue life difference shown in Fig. 3. As we mentioned above, the effect of the oxidation in the testing of the present study could not be so significant to produce the clear reduction of the fatigue life. However, the oxidized volume would not be so small when the fatigue tests reached to the final fracture stage. Moreover, the oxidized volume should be independent of the specimen size (RB-7 vs. RB-1). Thus, as shown in Fig. 6, the oxidized volume around the specimen cross-section including the main crack could not be negligible for the RB-1 specimen in comparison with the RB-7 specimen. Therefore, the slightly shorter fatigue life of the RB-1 specimen than the RB-7 specimen at $550{ }^{\circ} \mathrm{C}$ in air was attributed to the rapid crack propagation enhanced by the oxidation at the final fracture stage.

Finally, it could be concluded that the new high temperature low cycle fatigue testing machine of the present study could satisfy the minimum requirements for the high temperature low cycle fatigue life evaluation using small specimen. All the tests were stably performed for relatively long testing period. The fatigue life data of the F82H-IEA obtained using this testing machine could be acceptable based on the comparison with the fatigue life data by the previous studies. However, the effect of the "in-air" environment, especially the oxidation, would become significant at lower strain conditions with longer testing period. Therefore, the fatigue tests under much lower strain range conditions than the present study should be performed in future to clarify the entire structure of the oxidation effects

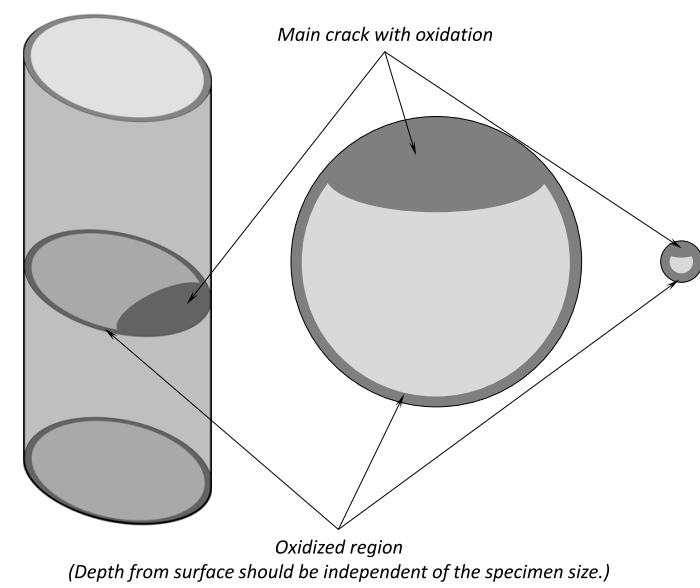

$\begin{array}{ccc}\begin{array}{c}\text { (a) 3D image of test section } \\ \text { of RB-7 specimen }\end{array} & \begin{array}{c}\text { (b) Cross-section 2D image } \\ \text { of test section of RB-7 }\end{array} & \begin{array}{c}\text { (c) Cross-section 2D image } \\ \text { of test section of RB-1 }\end{array} \\ \text { specimen } & \text { specimen }\end{array}$

Fig. 6 Schematic illustrations of oxidized region and main crack with oxidation of the RB-7 and RB-1 specimens reached to the final fracture stage.

on the fatigue life. Moreover, because the fusion reactor materials such as a blanket material generally utilized in vacuum environment, it must be clarified in future whether the high temperature fatigue life evaluation in air is conservative or not based on the comparison with the fatigue life obtained in vacuum.

\section{Conclusion}

For developing the high temperature fatigue life evaluation method using small specimen, the effect of specimen size and test environment (in air vs. in vacuum) on the 
high temperature fatigue life of the RAFM steel, F82HIEA, was investigated by the fatigue tests at $550{ }^{\circ} \mathrm{C}$ in air under the total strain range of $0.5-1.2 \%$ using round-bar specimens (test section diameter: $7 \mathrm{~mm}$ (RB-7 specimen) and $1 \mathrm{~mm}$ (RB-1 specimen)) and by the comparison with the fatigue life obtained in vacuum of the previous reports. The results of this study are summarized as follows:

1) In general, the fatigue life at $550{ }^{\circ} \mathrm{C}$ was $40-90 \%$ shorter than that at R.T. regardless of the specimen size and test environment.

2) The fatigue life of the RB- 7 specimen at $550{ }^{\circ} \mathrm{C} \mathrm{ob}$ tained in air was slightly longer than that obtained in vacuum. This result was opposite against the previous studies in general, which were explained by the oxidation-enhanced fatigue crack initiation and propagation. However, based on the fact that the difference between them was not so large and fact that the fatigue life reduction by the oxidation occurred under the low strain condition in the previous studies, it could be assumed that the effect of the oxidation on the fatigue life was relatively small or negligible under the test conditions of the present study.

3) The fatigue life at $550{ }^{\circ} \mathrm{C}$ in air of the RB-1 specimens was slightly shorter than that of the RB-7 specimens, which was attributed to the difference in the cyclic softening behavior at the final fracture stage. Because the oxidized volume of the specimen test section could not be negligible for the RB-1 specimen in comparison with the RB-7 specimen, it could be assumed that the slightly shorter fatigue life of the RB-1 specimen occurred due to the rapid crack propagation enhanced by the oxidation at the final fracture stage.

4) It could be concluded that the new high temperature low cycle fatigue testing machine of the present study could satisfy the minimum requirements for the high temperature low cycle fatigue life evaluation using small specimen. The fatigue life data obtained using this testing machine could be acceptable based on the comparison with the data of the previous studies.

\section{Acknowledgments}

This study was supported by the IFMIF/EVEDA (Engineering Validation and Engineering Design Activity) un- der the BA (Broader Approach) activity.

[1] S. Nogami, A. Nishimura, E. Wakai, H. Tanigawa, T. Itoh and A. Hasegawa, J. Nucl. Mater. 441, 125 (2013).

[2] S. Nogami, T. Itoh, H. Sakasegawa, H. Tanigawa, E. Wakai, A. Nishimura and A. Hasegawa, J. Nucl. Sci. Technol. 481, 60 (2011).

[3] S. Nogami, Y. Sato, A. Tanaka, A. Hasegawa, A. Nishimura and H. Tanigawa, J. Nucl. Sci. Technol. 47-1, 47 (2010).

[4] S. Nogami, Y. Sato, A. Hasegawa, H. Tanigawa, M. Yamazaki and M. Narui, J. Nucl. Mater. 417, 131 (2011).

[5] S. Nogami, Y. Sato, A. Hasegawa and H. Tanigawa, J. Plasma Fusion Res. SERIES 9, 232 (2010).

[6] S. Nogami, Y. Sato and A. Hasegawa, J. Nucl. Sci. Technol. 47-5, 457 (2010).

[7] S.W. Kim, H. Tanigawa, T. Hirose, K. Shiba and A. Kohyama, J. Nucl. Mater. 367-370, 568 (2007).

[8] H. Tanigawa, T. Hirose, M. Ando, S. Jitsukawa, Y. Katoh and A. Kohyama, J. Nucl. Mater. 307-311, 293 (2002).

[9] T. Hirose, H. Tanigawa, M. Ando, A. Kohyama, Y. Katoh and M. Narui, J. Nucl. Mater. 307-311, 304 (2002).

[10] T. Hirose, H. Sakasegawa, A. Kohyama, Y. Katoh and H. Tanigawa, J. Nucl. Mater. 283-287, 1018 (2000).

[11] T. Hirose, K. Shiba, T. Sawai, S. Jitsukawa and M. Akiba, J. Nucl. Mater. 329-333, 324 (2004).

[12] ASTM E112-85, "Standard Methods for Determining the Average Grain Size," (1986).

[13] K. Shiba, "Fatigue Properties of F82H IEA Heat," International Town Meeting on Advanced Ferritic Steel Design and Materials Issues for Fusion, San Diego, CA April 15, 2002.

[14] ASTM E606-04, "Standard Practice for Strain-Controlled Fatigue Testing," (2005).

[15] B. Fournier, M. Sauzay, C. Caës, M. Noblecourt, V. Rabeau, A. Bougault and A. Pineau, J. Nucl. Mater. 386388, 418 (2009).

[16] B. Fournier, M. Sauzay, C. Caës, M. Noblecourt, M. Mottot, A. Bougault, V. Rabeau, J. Man, O. Gillia, P. Lemoine and A. Pineau, Int. J. Fatigue 30, 1797 (2008).

[17] S. Kim and J.R. Weertman, Metall. Trans. A 19, 999 (1988).

[18] B. Fournier, M. Sauzay, C. Caës, M. Noblecourt, M. Mottot, A. Bougault, V. Rabeau and A. Pineau, Int. J. Fatigue 30, 649 (2008).

[19] B. Fournier, M. Sauzay, C. Caës, M. Noblecourt, M. Mottot, A. Bougault, V. Rabeau and A. Pineau, Int. J. Fatigue 30, 663 (2008).

[20] K. Hirakawa and K. Tokimasa, J. Soc. Mater. Sci. Jpn. 28308, 386 (1979). 